\title{
Association between motoric cognitive risk syndrome and frailty among older Chinese adults
}

Shanshan Shen, Xingkun Zeng, Liyu Xu, Lingyan Chen, Zixia Liu, Jiaojiao Chu, Yinghong Yang, Xiushao Wu and Xujiao Chen ${ }^{*}$

\begin{abstract}
Background: Motoric cognitive risk syndrome (MCR) is a newly proposed predementia syndrome incorporating subjective cognitive complaints and slow gait. Previous studies have reported that subjective cognitive complaints and slow gait are associated with frailty in cognitively unimpaired older adults, but little is known about the link between MCR and frailty in older adults. Therefore, the aim of the study was to explore the associations of MCR and its components with frailty in older Chinese adults.
\end{abstract}

Methods: In an observational cross-sectional study, a total of 429 older adults aged 60 years and older were admitted to the geriatric department. According to MCR criteria, all participants were classified into 4 groups: 1) the MCR group; 2) the subjective cognitive complaints only group; 3) the slow gait only group; and 4) the healthy control group. Physical frailty was assessed by the Clinical Frailty Scale (CFS). Multivariate logistic regression analysis was used to examine the association between MCR and frailty in older adults.

Results: The prevalence rates of subjective cognitive complaints, slow gait and MCR were 15.9, 10.0 and 4.0\%, respectively. After adjusting for confounding variables, the logistic regression analysis showed that slow gait (odds ratio [OR]: $3.40,95 \%$ confidence interval [Cl]: 1.40-8.23, $P=0.007$ ) and MCR (OR: 5.53, 95\% Cl: 1.46-20.89, $P=0.012$ ) were independently associated with frailty, but subjective cognitive complaints were not.

Conclusions: MCR and slow gait were significantly associated with frailty in older Chinese adults. Further studies should prospectively determine the causal relationship between MCR and frailty.

Keywords: Cognitive complaints, Slow gait, Frailty, Older adult

\section{Background}

Accelerated population ageing and increased average life expectancy in China are expected to further increase age-associated pathological conditions, such as cognitive impairment and frailty. Motoric cognitive risk syndrome (MCR) is a predementia syndrome that is characterized by the simultaneous presence of subjective cognitive complaints and slow gait in older individuals without

\footnotetext{
*Correspondence: lily197459@163.com

Department of Geriatric, Zhejiang Hospital, No. 12 Lingyin Road, Hangzhou 310013, Zhejiang Province, China
}

dementia or mobility disability [1]. The reported prevalence of MCR ranged from 2 to 18\% [2-7]. Based on the current studies, the lowest MCR prevalence was found in the Australian (2\%) and United Kingdom (2\%) populations; high prevalence rates were found in Japan (6.4\%), China (9.6\%), Mexico (14.6\%) and India (15\%); and the highest prevalence was seen in France (16-18\%) studies [2-7]. MCR was found to be associated with adverse clinical outcomes in older individuals, such as dementia, falls, disability and mortality $[1,8-11]$. A prospective cohort study based in the Einstein Aging Study

(C) The Author(s). 2020 Open Access This article is licensed under a Creative Commons Attribution 4.0 International License, which permits use, sharing, adaptation, distribution and reproduction in any medium or format, as long as you give appropriate credit to the original author(s) and the source, provide a link to the Creative Commons licence, and indicate if changes were made. The images or other third party material in this article are included in the article's Creative Commons licence, unless indicated otherwise in a credit line to the material. If material is not included in the article's Creative Commons licence and your intended use is not permitted by statutory regulation or exceeds the permitted use, you will need to obtain permission directly from the copyright holder. To view a copy of this licence, visit http://creativecommons.org/licenses/by/4.0/ The Creative Commons Public Domain Dedication waiver (http://creativecommons.org/publicdomain/zero/1.0/) applies to the data made available in this article, unless otherwise stated in a credit line to the data. 
showed that older adults with MCR had a greater than 3 -fold risk of developing dementia and a greater than 12-fold risk of vascular dementia [1]. A recent study from a Japanese community-dwelling sample of older adults reported that MCR was a risk factor for future dementia $(H R=2.49)$ and disability $(H R=1.69)$ [8]. Kumai and colleagues found that the rate of conversion to dementia in the MCR group was 1.38-times higher than that in the non-MCR group, and both slow gait and lower scores on executive tests were reported to be predictive of a higher rate of conversion to dementia [12]. In addition, because screening for MCR does not require complex neuropsychological tests or neuroimaging examinations, it is more conducive to increasing the accessibility of clinical dementia risk assessment and implementing appropriate prevention strategies. Therefore, MCR has increasingly gained clinical attention.

Frailty is a common geriatric syndrome that is partially reversible and characterized by age-related decline in physiologic reserves and function of multiple systems, resulting in increasing vulnerability triggered by minor stressor events and further leading to negative health outcomes, including falls, disability, hospitalization and mortality [13-15]. A growing body of evidence has shown that cognitive impairment and frailty are closely related in populations with advanced age in that they may share similar etiologies. For example, frail status may increase the risk of cognitive decline, incident mild cognitive impairment and dementia [16-20]. Alternatively, cognitive impairment also increases the risk of frailty $[21,22]$. Frailty and cognitive impairment often coexist $[23,24]$, so the construct of cognitive frailty was proposed, which is also described as a risk factor for dementia $[25,26]$.

Compared with the operational definition of cognitive frailty incorporating physical frailty and cognitive impairment without an overt dementia diagnosis, MCR focuses more on subjective cognitive complaints but not mild cognitive impairment (MCI) [27]. Subjective cognitive complaints with normal objective cognitive test results indicate the presence of subjective cognitive decline [28]. Subjective cognitive decline has been reported to be predictive of incident MCI [29], as well as dementia [30]. Thus, MCR might represent an earlier stage of preclinical dementia. Additionally, although subjective cognitive decline and slow gait are reported to be associated with frailty in cognitively unimpaired older adults [24, 25,31 , little is known about the link between MCR and frailty in older adults. Based on these studies, we hypothesized that older adults with MCR may exhibit a higher risk of frailty than older adults with subjective cognitive complaints or slow gait. Therefore, we conducted this study to explore the associations of MCR and its components with frailty in older Chinese adults.

\section{Methods}

\section{Participants}

An observational cross-sectional study was carried out with a total of 935 potential participants from the geriatric department of Zhejiang Hospital in China, and the baseline assessments were performed from October 2014 to September 2018. The inclusion criteria in this study were an age of 60 years or older and the ability to understand and communicate in Chinese. Participants with a history of Parkinson's disease, Parkinson's syndrome, dementia, MCI indicated by a score lower than 24 on the Mini-Mental State Examination (MMSE) or mobility disability [1] who were unable to ambulate with or without walking aids were excluded. Participants who had incomplete data used to diagnose MCR were also excluded. Data were collected by a trained geriatric physician and nurse via a computeraided hospital-based comprehensive geriatric assessment.

Approval for this study was granted by the medical ethics committees of Zhejiang Hospital (2013-25), and written informed consent was obtained from each participant. This study has not been registered, and the manuscript was written according to the STrengthening the Reporting of OBservational studies in Epidemiology (STROBE) statement.

\section{MCR diagnosis}

Based on the MCI operational definition [32, 33], Verghese and colleagues proposed the MCR concept [1]. MCR was diagnosed as both the presence of subjective cognitive complaints and slow gait in those without dementia or mobility disability [1]. Subjective cognitive complaints were determined by face-to-face interviews based on responses to one item on a 15-item geriatric depression scale (GDS-15) [34]. The standardized question "Do you feel you have more problems with memory than most?" was asked by a welltrained nurse. A positive response "yes" on this question indicated a subjective cognitive complaint. Gait speed $(\mathrm{m} / \mathrm{s})$ was calculated by the four-metre usual gait speed test. The participants completed the test twice while starting from an inactive standing position (walking aids or cane allowed), and the shortest time was recorded. Slow gait was defined as gait speed one standard deviation below the age- and sex-specific means [1]. The cut-off values of slow gait in this study were: males $60-74$ years $\leq 0.91 \mathrm{~m} / \mathrm{s}$, males $\geq 75$ years $\leq 0.69 \mathrm{~m} / \mathrm{s}$, females $60-74$ years $\leq 0.80 \mathrm{~m} / \mathrm{s}$, females $\geq 75$ years $\leq 0.66 \mathrm{~m} / \mathrm{s}$.

According to the MCR criteria, all participants were classified to 4 groups: 1 ) the MCR group; 2 ) the subjective cognitive complaints only group; 3 ) the slow gait only group; and 4) the healthy control group.

\section{Frailty assessment}

Based on the Canadian study on Health and Aging, frailty was assessed by the Clinical Frailty Scale (CFS), which was scored from 1 (very fit) to 7 (severely frail) [35, 36]. The 
evaluator recorded the level of frailty using their clinical judgement based on available clinical information. In this study, a CFS score greater than four indicated frailty [37].

The CFS was assessed by a well-trained assessor who was qualified in geriatric comprehensive assessment. There are three qualified members in our team, and they had evaluated a total of 1122 cases. The CFS assessor was blinded to the MCR assessor results.

\section{Other covariates}

Demographic data including age, sex, educational level, marital status, cigarette smoking and alcohol drinking use were obtained. Smoking status was categorized into nonsmokers, former smokers and current smokers on the basis of self-reported amount and length of cigarette smoking. Current smokers were those who smoked regularly at least once a day or more for more than half a year, and former smokers were those who used to smoke but stopped smoking at least half a year prior to the study [38]. Alcohol drinking status was classified into non-drinkers, former drinkers and current drinkers based on the self-reported amount and duration of alcoholic beverages. Current drinkers were those who drank at least once a week for more than 6 months, and former drinkers were defined those who stopped drinking at least 6 months prior to the start of the study [38]. Body mass index (BMI) was calculated with height and weight. Physician-diagnosed chronic medical diseases were recorded according to the International Classification of Diseases, Tenth Revision (ICD10) codes. Diabetes mellitus, cerebrovascular diseases, hypertension and coronary artery disease were included in this study. Comorbidities were defined as the coexistence of five kinds of chronic diseases or more. Participants who took five or more oral prescription medications were considered to the polypharmacy criteria [39]. A history of falls in the past year was also recorded. A fall was defined as a sudden, involuntary, unintentional change of position resulting in rest on the ground or another lower plane [40]. Dominant hand grip strength was measured three times using a hand dynamometer. The maximum of the three measurements was recorded for the final analysis. Depression symptoms were evaluated using the GDS-15 [34] and cognitive function was assessed using the MMSE [41].

\section{Statistical analysis}

Normal distributed continuous variables are presented as the means \pm standard deviations (SDs), and categorical variables are expressed as numbers (percentages). The unpaired t-test (for normally distributed continuous data) and the chi-square test (for categorical data) were used to identify the significant differences between the male and female groups. One-way ANOVA (for normally distributed continuous data) and the chi-square test (for categorical data) were used to identify the significant differences among the control, subjective cognitive complaints only, slow gait only and MCR groups. Furthermore, the association of MCR with frailty was analysed using multivariate logistic regression models and expressed in odds ratios (ORs) and 95\% confidence intervals (CIs). Multivariate logistic regression was conducted with 3 models. Model 1 was not adjusted covariates; Model 2 was adjusted for age, sex and education; and Model 3 was adjusted for marital status, BMI, comorbidities, polypharmacy, fall history, grip strength, depressive symptoms and MMSE scores, in addition to the variables adjusted in Model 2. The data were analysed by using SPSS 18.0 software (SPSS, Chicago, IL, USA). All significance tests were two-tailed, and statistical significance was indicated by $P<0.05$.

\section{Results}

\section{Enrolment, prevalence rates and characteristics of the} total sample

Figure 1 shows the flow chart of participant selection. A total of 935 potential participants were screened, and after exclusions, 429 patients were finally eligible.

The characteristics of the 429 participants are presented in Table 1. The mean age of the participants was $76.7( \pm$ 7.7) years, $59.9 \%$ were male, $66.0 \%$ had an educational level of high school or above and $79.3 \%$ were married. The mean BMI was $23.7( \pm 3.2) \mathrm{kg} / \mathrm{m}^{2}$. More than half $(60.4 \%)$ of the participants reported 5 or more comorbid conditions, and hypertension (75.8\%) was the most common chronic disease. Nearly half of the participants (46.2\%) met the criteria for polypharmacy. Approximately $15 \%$ of participants were classified as physically frail. Compared with males, females were older, had a lower educational level, were more often married, had a higher percentage of smoking and drinking history, had lower grip strength and were more likely to have depressive symptoms (all $P$ for trend $<0.05$ ), as detailed in Table 1 . The distribution of CFS scores is shown in Fig. 2.

Of the total participants, the prevalence rates of subjective cognitive complaints only, slow gait only and MCR were 15.9, 10.0 and 4.0\%, respectively.

\section{Comparing variables between groups}

As shown in Table 2, significant differences were observed among the four groups (i.e., the control, subjective cognitive complaints only, slow gait only and MCR groups) with regard to BMI, polypharmacy, grip strength, four-metre gait speed, GDS-15 scores, MMSE scores and physical frailty (all $P$ for trend $<0.05$ ). There were no significant differences in age, sex, educational level, marital status, smoking history, alcohol drinking history, comorbid diseases (such as diabetes mellitus, cerebrovascular diseases, hypertension and coronary artery disease) or fall history in the past year among the groups (all $P$ for trend $>0.05$ ). 


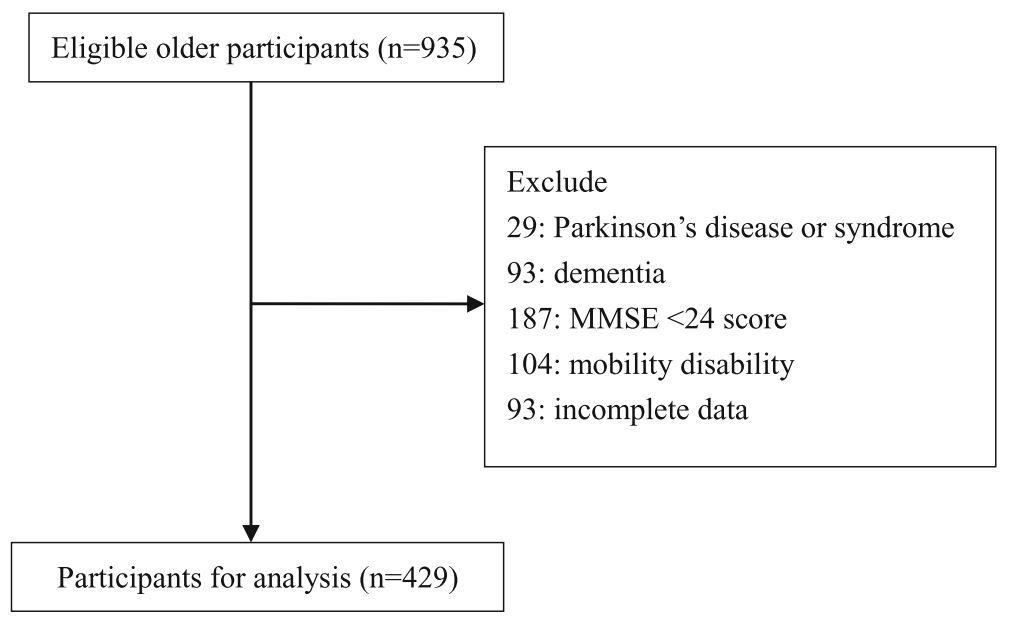

Fig. 1 Flow chart of participant selection

The association between MCR and frailty

Table 3 shows the results of the multivariate logistic regression analysis on the association between MCR and frailty. Crude Model 1 showed that slow gait (OR: 4.81, 95\% CI: 2.35-9.85) and MCR (OR: 7.22, 95\% CI: 2.61-19.99) were associated with frailty. Model 2, after adjusting for age, sex and education, showed that slow gait (OR: 4.36, 95\% CI: 1.94-9.80) and MCR (OR: 9.98, 95\% CI: 2.88-34.59) remained associated with frailty. In the fully adjusted Model
3 , the results remained unchanged, and slow gait (OR: 3.40 , 95\% CI: $1.40-8.23$ ) and MCR (OR: 5.53, 95\% CI: $1.46-$ 20.89) were associated with an increased risk of frailty. However, no significant association was found between subjective cognitive complaints and frailty.

\section{Discussion}

In this study, MCR and slow gait were both significantly associated with frailty in older adults in the geriatric

Table 1 Characteristics and comparing in male and female

\begin{tabular}{|c|c|c|c|c|}
\hline & $\begin{array}{l}\text { Total } \\
(n=429)\end{array}$ & $\begin{array}{l}\text { Males } \\
(n=257)\end{array}$ & Females $(n=172)$ & $P$-value \\
\hline Age, years (mean $\pm S D$ ) & $76.7 \pm 7.7$ & $77.4 \pm 8.0$ & $75.7 \pm 7.2$ & 0.027 \\
\hline High school and above, $n$ (\%) & $283(66.0)$ & $179(69.6)$ & $104(60.5)$ & 0.049 \\
\hline Married, $n(\%)$ & $340(79.3)$ & $221(86.0)$ & $119(69.2)$ & $<0.001$ \\
\hline Current or former smoker, $n(\%)$ & $100(23.3)$ & $100(38.9)$ & $0(0)$ & $<0.001$ \\
\hline Current or former drinker, $n$ (\%) & $99(23.1)$ & $93(36.2)$ & $6(3.5)$ & $<0.001$ \\
\hline $\mathrm{BMI}\left(\right.$ mean $\left.\pm \mathrm{SD}, \mathrm{kg} / \mathrm{m}^{2}\right)$ & $23.7 \pm 3.2$ & $23.8 \pm 3.0$ & $23.5 \pm 3.5$ & 0.312 \\
\hline History of diabetes, $n$ (\%) & $101(23.5)$ & $64(24.9)$ & $37(21.5)$ & 0.417 \\
\hline History of cerebrovascular diseases, $n$ (\%) & $129(30.1)$ & $78(30.4)$ & $51(29.7)$ & 0.877 \\
\hline History of hypertension, $n$ (\%) & $325(75.8)$ & $199(77.4)$ & $126(73.3)$ & 0.323 \\
\hline History of coronary artery disease, $n(\%)$ & $141(32.9)$ & $85(33.1)$ & $56(32.6)$ & 0.911 \\
\hline Comorbidities ( $\geq 5$ diseases), $n$ (\%) & $259(60.4)$ & $157(61.1)$ & $102(59.3)$ & 0.711 \\
\hline Polypharmacy ( $\geq 5$ drugs), $n$ (\%) & $198(46.2)$ & $118(45.9)$ & $80(46.5)$ & 0.903 \\
\hline Fall history in the past year, $n(\%)$ & $69(16.1)$ & $41(16.0)$ & $28(16.3)$ & 0.928 \\
\hline Grip strength, (mean \pm SD, kg) & $30.6 \pm 9.4$ & $35.5 \pm 8.1$ & $23.3 \pm 5.5$ & $<0.001$ \\
\hline Four-meter usual gait speed (mean $\pm S D, m / s$ ) & $1.0 \pm 0.3$ & $1.0 \pm 0.3$ & $1.0 \pm 0.3$ & 0.622 \\
\hline Depressive symptoms from GDS-15 (mean \pm SD, scores) & $2.2 \pm 2.4$ & $1.8 \pm 2.1$ & $2.9 \pm 2.8$ & $<0.001$ \\
\hline MMSE (mean $\pm S D$, scores) & $27.4 \pm 1.9$ & $27.3 \pm 1.9$ & $27.5 \pm 1.8$ & 0.145 \\
\hline Frailty for CFS $\geq 5, n(\%)$ & $64(14.9)$ & $38(14.8)$ & $26(15.1)$ & 0.925 \\
\hline
\end{tabular}

Abbreviations: $B M I$ body mass index, GDS-15 15-item Geriatric Depression Scale, MMSE Mini-Mental State Examination, CFS Clinical Frailty Scale. The P-value is for comparing sex differences 


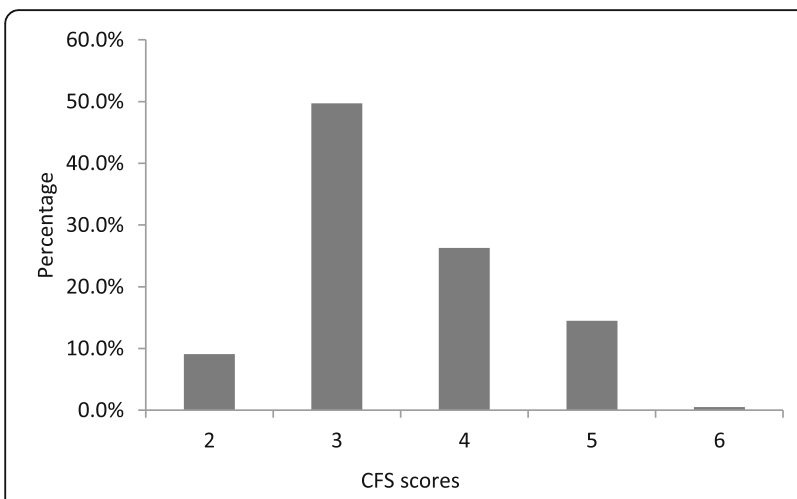

Fig. 2 Distribution of CFS scores in the total sample

department, but subjective cognitive complaints were not associated with frailty. These associations remained unchanged after adjusting for potential confounding variables. These results revealed that the association between MCR and frailty was commonly observed along with slow gait, and the combination of subjective cognitive complaints and slow gait may have greater predictive value than the single component to explain their common association with frailty.

The primary finding of this study is that MCR was associated with frailty in elderly population. This finding is in accordance with a cross-sectional study from France [42], which showed that physical frailty and, in particular, slow gait speed were associated with cognitive impairment, indirectly reflecting that slow gait and cognitive impairment often coexist with MCR and suggesting that MCR and frailty interact with each other in the context of ageing. Subjective cognitive complaints and slow gait are common conditions in the ageing process and have been considered early clinical indicators of cognitive impairment and dementia during the preclinical stages. Cognitive impairment is a longitudinal process that begins with minor alterations in certain domains and slowly progresses to multiple changes in many domains [43]. The accumulation of cerebral amyloid deposition and neurofibrillary tangles plays a critical role in the progression of Alzheimer's disease neuropathology $[44,45]$. In addition, alterations in brain regions, including the motor cortices, striatum and substantia nigra are often involved [44, 45]. Studies have shown that MCR involves a wider range of brain regions and that its involvement is not limited to the hippocampus, which is a key brain region for memory and spatial navigation processes [46-48]. MCR has been characterized by smaller volumes of total grey matter, total cortical grey matter, the premotor cortex, and the prefrontal cortex, especially the dorsolateral segment; however, no significant differences were found in terms of the volumes of hippocampal and white matter $[49,50]$, which is in concordance with these results as these two components control cognitive complaints and slow gait. MCR-related

Table 2 Characteristics and comparing among the four groups

\begin{tabular}{|c|c|c|c|c|c|}
\hline & $\begin{array}{l}\text { Healthy control } \\
(n=301)\end{array}$ & $\begin{array}{l}\text { Subjective cognitive } \\
\text { complaints only }(n=68)\end{array}$ & $\begin{array}{l}\text { Slow gait only } \\
(n=43)\end{array}$ & $\operatorname{MCR}(n=17)$ & $P$-value \\
\hline Age, years (mean $\pm S D$ ) & $76.6 \pm 7.6$ & $75.7 \pm 7.8$ & $79.1 \pm 7.7$ & $76.7 \pm 8.7$ & 0.156 \\
\hline Male, $n(\%)$ & $189(62.8)$ & $34(50.0)$ & $27(62.8)$ & $7(41.2)$ & 0.092 \\
\hline High school and above, $n$ (\%) & $207(68.8)$ & $40(58.8)$ & $28(65.1)$ & $8(47.1)$ & 0.150 \\
\hline Married, $n(\%)$ & $239(79.4)$ & $58(85.3)$ & $29(67.4)$ & $14(82.4)$ & 0.154 \\
\hline Current or former smoker, $n(\%)$ & $73(24.3)$ & $15(22.1)$ & $9(20.9)$ & $3(17.6)$ & 0.885 \\
\hline Current or former drinker, $n(\%)$ & $74(24.6)$ & $13(19.1)$ & $9(20.9)$ & $3(17.6)$ & 0.710 \\
\hline $\mathrm{BMI}\left(\right.$ mean $\left.\pm \mathrm{SD}, \mathrm{kg} / \mathrm{m}^{2}\right)$ & $23.7 \pm 3.0$ & $22.8 \pm 3.1$ & $24.5 \pm 3.8$ & $24.4 \pm 4.5$ & 0.032 \\
\hline History of diabetes, $n$ (\%) & $76(25.2)$ & $8(11.8)$ & $13(30.2)$ & $4(23.5)$ & 0.079 \\
\hline History of cerebrovascular diseases, $n$ (\%) & $86(28.6)$ & $19(27.9)$ & $15(34.9)$ & $9(52.9)$ & 0.160 \\
\hline History of hypertension, $n$ (\%) & $223(74.1)$ & $52(76.5)$ & $36(83.7)$ & $14(82.4)$ & 0.500 \\
\hline History of coronary artery disease, $n(\%)$ & $93(30.9)$ & $24(35.3)$ & $15(34.9)$ & $9(52.9)$ & 0.273 \\
\hline Comorbidities ( $\geq 5$ diseases), $n$ (\%) & $176(58.5)$ & $42(61.8)$ & $29(67.4)$ & $12(70.6)$ & 0.542 \\
\hline Polypharmacy ( $\geq 5$ drugs), $n$ (\%) & $132(43.9)$ & $27(39.7)$ & $27(62.8)$ & $12(70.6)$ & 0.014 \\
\hline Fall history in the past year, $n(\%)$ & $50(16.6)$ & $10(14.7)$ & $8(18.6)$ & $1(5.9)$ & 0.643 \\
\hline Grip strength, (mean $\pm S D, k g)$ & $31.8 \pm 9.2$ & $29.7 \pm 8.8$ & $26.8 \pm 9.7$ & $23.0 \pm 6.8$ & $<0.001$ \\
\hline Four-meter usual gait speed (mean $\pm \mathrm{SD}, \mathrm{m} / \mathrm{s}$ ) & $1.1 \pm 0.2$ & $1.1 \pm 0.2$ & $0.6 \pm 0.1$ & $0.6 \pm 0.2$ & $<0.001$ \\
\hline Depressive symptoms from GDS-15 (mean $\pm \mathrm{SD}$, scores) & $1.6 \pm 2.0$ & $4.0 \pm 2.7$ & $2.7 \pm 2.4$ & $5.1 \pm 2.9$ & $<0.001$ \\
\hline MMSE (mean $\pm S D$, scores) & $27.6 \pm 1.8$ & $27.2 \pm 1.8$ & $26.9 \pm 2.0$ & $25.7 \pm 1.7$ & $<0.001$ \\
\hline Frailty for CFS $\geq 5, n(\%)$ & $33(11.0)$ & $7(10.3)$ & $16(37.2)$ & $8(47.1)$ & $<0.001$ \\
\hline
\end{tabular}

Abbreviations: BMI body mass index, GDS-15 15-item Geriatric Depression Scale, MMSE Mini-Mental State Examination, CFS Clinical Frailty Scale 
Table 3 Multivariate analysis of the association between MCR and physical frailty

\begin{tabular}{|c|c|c|c|c|c|c|}
\hline & \multicolumn{2}{|l|}{ Model 1} & \multicolumn{2}{|l|}{ Model 2} & \multicolumn{2}{|l|}{ Model 3} \\
\hline & OR(95\%Cl) & $P$-value & OR(95\%Cl) & $P$-value & $\mathrm{OR}(95 \% \mathrm{Cl})$ & $P$-value \\
\hline Healthy control & 1.00 & - & 1.00 & - & 1.00 & - \\
\hline Subjective cognitive complaints only & $0.93(0.39-2.21)$ & 0.873 & $1.03(0.41-2.56)$ & 0.952 & $0.76(0.26-2.26)$ & 0.619 \\
\hline Slow gait only & $4.81(2.35-9.85)$ & $<0.001$ & $4.36(1.94-9.80)$ & $<0.001$ & $3.40(1.40-8.23)$ & 0.007 \\
\hline MCR & $7.22(2.61-19.99)$ & $<0.001$ & $9.98(2.88-34.59)$ & $<0.001$ & $5.53(1.46-20.89)$ & 0.012 \\
\hline
\end{tabular}

Abbreviations: $O R$ odd ratio, $C l$ confidence interval, $B M I$ body mass index

Notes: Model 1: crude model; Model 2: adjusted for age, sex and education; Model 3: adjusted for Model 2 plus BMI, comorbidities, polypharmacy, grip strength, depressive symptoms and MMSE scores

brain region reduction contributes more to the prediction of cortical neurodegenerative dementia than that of subcortical dementia, such as vascular dementia [49]. A study by Wang and colleagues found that frontal lacunar infarcts were associated with slow gait, poor memory function and MCR, but not with cognitive complaints [51], revealing that this brain area might result in MCR by disrupting frontally based neural networks facilitating memory and gait functions $[52,53]$. On the other hand, the accumulation of common brain pathologies and related brain area alterations may also contribute to progressive frailty [54, 55]. Cerebral amyloid-beta deposition and neurofibrillary tangles were associated with symptoms of frailty, including slower gait speed and lower body mass index in dementia-free elderly individuals $[56,57]$. Thus, the association between MCR and frailty could be explained by the abovementioned mechanisms. Slow gait speed is an indicator of physical frailty in the elderly population, which can explain the association between slow gait and frailty in our samples. However, the lack of longitudinal prospective studies of the causal associations between MCR and frailty prevents conclusions from being drawn.

The association between subjective cognitive complaints and frailty was not observed in this study sample. This finding was inconsistent with the results of previous studies, such as the Hellenic Longitudinal Investigation of Aging and Diet study [31] and the Healthy Aging Longitudinal Study in Taiwan [24], revealing that subjective cognitive decline was associated with an increased likelihood of frailty in cognitively unimpaired elderly individuals. Self-reported measures of subjective cognitive decline complaints were adopted, but discrepant results were obtained due to the differences in frailty assessment criteria to determine frailty status. In addition, the characteristics of the enrolled study sample were inconsistent. The potential neurobiological explanations for the association between subjective cognitive decline and frailty include that both factors increase the risk of future cognitive decline $[16,17,29,30]$ and Alzheimer's disease pathology [58-61].

An important advantage of this study is that all the enrolled older participants underwent a comprehensive geriatric assessment focusing on the functional status of elderly individuals, such as activities of daily living, cognition and frailty. Indeed, in our geriatric department, we have a trained team for comprehensive geriatric assessment, and all the assessments are designed to be conducted with a professional software system. Thus, the validity and consistency of the evaluations are guaranteed. Another advantage is that MCR and CFS-defined frailty screening in this study are relatively simple and easy to implement in other clinical settings, such as community health service centres and other primary medical centres. CFS was reported to reflect the dynamic and reversible changes in frailty and was strongly associated with the frailty index. Thus, it can similarly predict adverse outcomes for elderly patients [35, 62]. In contrast, this study also has some limitations. First, although this study is the first to report the association between MCR and frailty in an older Chinese population, the cross-sectional nature of study precluded us from elucidating the causal relationships. Second, due to the use of a convenience sampling method for the recruitment of inpatients in a monocentric study and the relatively small sample size of MCR cases, there are selection and a representativeness biases in this study. Third, although these study participants were in the normal MMSE range, some participants with mild hidden dementia might be undiagnosed. Finally, the standard definition of MCR is also a limitation of this study. The definition of slow gait is already standardized, but subjective cognitive complaints have not been standardized. Subjective cognitive complaints were defined by one item of the GDS-15 in this study according to the standard method in most studies. Furthermore, the accuracy of self-reported cognitive complaints may be affected by the disease, emotional and environmental factors. Thus, the generalization of the study results could not be assumed because the results are less sensitive for non-demented older adults.

\section{Conclusions}

Our results support the idea that MCR and slow gait were associated with frailty in older adults without dementia or mobility disability. Further study is needed to better understand the pathophysiological, behavioural and environmental variables to prospectively determine the causal relationship between MCR and frailty in a 
multicenter study with a large sample. More research is also necessary to develop new interventions and preventative strategies for improving quality of life and reducing or reversing cognitive impairments and frailty in older adults.

\section{Abbreviations}

MCR: Motoric cognitive risk; CFS: Clinical Frailty Scale; MCl: Mild cognitive impairment; BMI: Body mass index; MMSE: Mini-Mental State Examination; GDS-15: 15-item Geriatric Depression Scale; SD: Standard deviation; OR: Odds ratio: Cl: Confidence interval

\section{Acknowledgements}

We would like to acknowledge the staff from the geriatric department of Zhejiang Hospital for their positive involvement in this study.

\section{Authors' contributions}

SS and XC participated in the study design, coordination and data analyses. $X Z$ and LX participated in MCR diagnosis; LC, ZL, and JC contributed to CGA: and $Y Y$ and $X W$ were responsible for data collection and management. SS wrote the original manuscript, and all the authors participated in interpreting the results, and revised and approved the final manuscript

\section{Funding}

This study was supported by the National Health and Family Planning Commission of Scientific Research Fund of People's Republic of China (WKJ2013-2-001), the Innovation Disciplines of Zhejiang Province, the Science Technology Department of Zhejiang Province (2014C33241), the Zhejiang Medical Science and Technology Project (2016ZDB001, 2018ZH001) and the "1530" personnel training project from Zhejiang Hospital (2018-3009).

\section{Availability of data and materials}

The datasets used and/or analysed during the current study are available from the corresponding author on reasonable request.

\section{Ethics approval and consent to participate}

The medical ethics committees of Zhejiang Hospital (2013-25) approved the entire study and written informed consent was obtained from each participant.

\section{Consent for publication}

Not applicable.

\section{Competing interests}

The authors declare that they have no competing interests.

Received: 12 September 2019 Accepted: 10 March 2020

Published online: 19 March 2020

\section{References}

1. Verghese J, Wang C, Lipton RB, et al. Motoric cognitive risk syndrome and the risk of dementia. J Gerontol A Biol Med Sci. 2013;68(4):412-8.

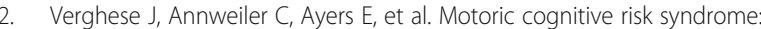
multicountry prevalence and dementia risk. Neurology. 2014;83(8):718-26.

3. Verghese J, Ayers E, Barzilai N, et al. Motoric cognitive risk syndrome: multicenter incidence study. Neurology. 2014;83(24):2278-84.

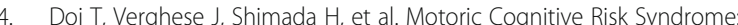
Prevalence and Risk Factors in Japanese Seniors. J Am Med Dir Assoc. 2015; 16(12):1103 e21-5.

5. Sekhon $H$, Allali $G$, Launay $C P$, et al. The spectrum of pre-dementia stages: cognitive profile of motoric cognitive risk syndrome and relationship with mild cognitive impairment. Eur J Neurol. 2017;24(8):1047-54.

6. Aguilar-Navarro SG, Mimenza-Alvarado AJ, Aguilar-Esquivel JE, et al. Motoric cognitive risk syndrome: prevalence and risk of cognitive impairment in a population studied in the Mexican health and aging study 2012-2015. J Nutr Health Aging. 2019;23(3):227-31

7. Chhetri JK, Han C, Dan X, et al. Motoric cognitive risk syndrome in a Chinese older adult population: prevalence and associated factors. J Am Med Dir Assoc. 2020;21(1):136-7.
8. Doi $\mathrm{T}$, Shimada $\mathrm{H}$, Makizako $\mathrm{H}$, et al. Motoric cognitive risk syndrome: association with incident dementia and disability. J Alzheimers Dis. 2017; 59(1):77-84

9. Callisaya ML, Ayers E, Barzilai N, et al. Motoric cognitive risk syndrome and falls risk: a multi-center study. J Alzheimers Dis. 2016;53(3):1043-52.

10. Ayers $\mathrm{E}$, Verghese J. Motoric cognitive risk syndrome and risk of mortality in older adults. Alzheimers Dement. 2016;12(5):556-64.

11. Beauchet $\mathrm{O}$, Sekhon $\mathrm{H}$, Launay $\mathrm{CP}$, et al. Motoric cognitive risk syndrome and mortality: results from the EPIDOS cohort. Eur J Neurol. 2019;26(5):794e56.

12. Kumai K, Meguro K, Kasai M, et al. Neuroepidemiologic and neurobehavioral characteristics of motoric cognitive risk syndrome in an old-old population: the Kurihara project. Dement Geriatr Cogn Dis Extra. 2016;6(2):176-82.

13. Fried LP, Tangen CM, Walston J, et al. Frailty in older adults: evidence for a phenotype. J Gerontol A Biol Med Sci. 2001:56(3):M146-56.

14. Clegg A, Young J, lliffe S, et al. Frailty in elderly people. Lancet. 2013; 381(9868):752-62.

15. Lee $Y$, Kim J, Chon D, et al. The effects of frailty and cognitive impairment on 3-year mortality in older adults. Maturitas. 2018;107:50-5.

16. Chong MS, Tay L, Chan M, et al. Prospective longitudinal study of frailty transitions in a community-dwelling cohort of older adults with cognitive impairment. BMC Geriatr. 2015;15:175.

17. Ma $L$, Zhang $L$, Sun $F$, et al. Cognitive function in Prefrail and frail community-dwelling older adults in China. BMC Geriatr. 2019;19(1):53.

18. Samper-Ternent R, Al Snih S, Raji MA, et al. Relationship between frailty and cognitive decline in older Mexican Americans. J Am Geriatr Soc. 2008;56(10): 1845-52.

19. Buchman AS, Boyle PA, Wilson RS, et al. Frailty is associated with incident Alzheimer's disease and cognitive decline in the elderly. Psychosom Med. 2007;69(5):483-9.

20. Boyle PA, Buchman AS, Wilson RS, et al. Physical frailty is associated with incident mild cognitive impairment in community-based older persons. J Am Geriatr Soc. 2010;58(2):248-55.

21. Han ES, Lee $Y$, Kim J. Association of cognitive impairment with frailty in community-dwelling older adults. Int Psychogeriatr. 2014;26(1):155-63.

22. Raji MA, Al Snih S, Ostir GV, et al. Cognitive status and future risk of frailty in older Mexican Americans. J Gerontol A Biol Med Sci. 2010;65(11):1228-34.

23. Shimada $H$, Makizako $H$, Doi $T$, et al. Combined prevalence of frailty and mild cognitive impairment in a population of elderly Japanese people. J Am Med Dir Assoc. 2013;14(7):518-24.

24. Malmstrom TK, Morley JE. The frail brain. J Am Med Dir Assoc. 2013;14(7):453-5.

25. Panza F, D'Introno A, Colacicco AM, et al. Cognitive frailty: Predementia syndrome and vascular risk factors. Neurobiol Aging. 2006;27(7):933-40.

26. Solfrizzi V, Scafato E, Seripa D, et al. Reversible Cognitive Frailty, Dementia, and All-Cause Mortality. The Italian Longitudinal Study on Aging. J Am Med Dir Assoc. 2017;18(1):89 e1-8

27. Kelaiditi E, Cesari M, Canevelli M, et al. Cognitive frailty: rational and definition from an (I.a.N.a./l.a.G.G.) international consensus group. J Nutr Health Aging. 2013:17(9):726-34.

28. Jessen $F$, Amariglio RE, van Boxtel M, et al. A conceptual framework for research on subjective cognitive decline in preclinical Alzheimer's disease. Alzheimers Dement. 2014;10(6):844-52.

29. Muller-Gerards D, Weimar C, Abramowski J, et al. Subjective cognitive decline, APOE epsilon4, and incident mild cognitive impairment in men and women. Alzheimers Dement. 2019:11:221-30.

30. Cosentino S, Metcalfe J, Holmes B, et al. Finding the self in metacognitive evaluations: metamemory and agency in nondemented elders. Neuropsychology. 2011;25(5):602-12.

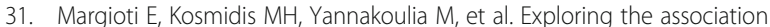
between subjective cognitive decline and frailty: the Hellenic longitudinal investigation of aging and diet study (HELIAD). Aging Ment Health. 2020; 24(1):137-47.

32. Albert MS, DeKosky ST, Dickson D, et al. The diagnosis of mild cognitive impairment due to Alzheimer's disease: recommendations from the National Institute on Aging-Alzheimer's Association workgroups on diagnostic guidelines for Alzheimer's disease. Alzheimers Dement. 2011;7(3):270-9.

33. Petersen RC. Clinical practice. Mild cognitive impairment. N Engl J Med. 2011:364(23):2227-34

34. Dennis M, Kadri A, Coffey J. Depression in older people in the general hospital: a systematic review of screening instruments. Age Ageing. 2012 41(2):148-54. 
35. Rockwood K, Song X, Macknight C, et al. A global clinical measure of fitness and frailty in elderly people. CMAJ. 2005;173(5):489-95.

36. Chen $L, X u Y, C$ Chen $X J$, et al. Association between orthostatic hypotension and frailty in hospitalized older patients: a geriatric syndrome more than a cardiovascular condition. J Nutr Health Aging. 2019;23(4):318-22.

37. Kahlon S, Pederson J, Majumdar SR, et al. Association between frailty and 30-day outcomes after discharge from hospital. CMAJ. 2015;187(11):799-804.

38. Liu $P, X u Y$, Tang $Y$, et al. Independent and joint effects of moderate alcohol consumption and smoking on the risks of non-alcoholic fatty liver disease in elderly Chinese men. PLoS One. 2017;12(7):e0181497.

39. Viktil KK, Blix HS, Moger TA, et al. Polypharmacy as commonly defined is an indicator of limited value in the assessment of drug-related problems. $\mathrm{Br} \mathrm{J}$ Clin Pharmacol. 2007;63(2):187-95.

40. Lamb SE, Jorstad-Stein EC, Hauer K, et al. Development of a common outcome data set for fall injury prevention trials: the prevention of falls network Europe consensus. J Am Geriatr Soc. 2005;53(9):1618-22.

41. Folstein MF, Folstein SE, McHugh PR. "mini-mental state". A practical method for grading the cognitive state of patients for the clinician. J Psychiatr Res. 1975;12(3):189-98.

42. Fougere B, Daumas M, Lilamand M, et al. Association Between Frailty and Cognitive Impairment: Cross-Sectional Data From Toulouse Frailty Day Hospital. J Am Med Dir Assoc. 2017;18(11):990 e1-5.

43. Atkinson $\mathrm{HH}$, Cesari M, Kritchevsky SB, et al. Predictors of combined cognitive and physical decline. J Am Geriatr Soc. 2005;53(7):1197-202.

44. Burns JM, Galvin JE, Roe CM, et al. The pathology of the substantia nigra in Alzheimer disease with extrapyramidal signs. Neurology. 2005;64(8):1397403.

45. Wolf DS, Gearing M, Snowdon DA, et al. Progression of regional neuropathology in Alzheimer disease and normal elderly: findings from the Nun study. Alzheimer Dis Assoc Disord. 1999;13(4):226-31.

46. Perri R, Monaco M, Fadda L, et al. Neuropsychological correlates of behavioral symptoms in Alzheimer's disease, frontal variant of frontotemporal, subcortical vascular, and lewy body dementias: a comparative study. J Alzheimers Dis. 2014;39(3):669-77.

47. Jenkins A, Bayer A, Tree J, et al. Self-reported memory complaints: implications from a longitudinal cohort with autopsies. Neurology. 2015; 84(23):2384.

48. Dubois B, Feldman HH, Jacova $\mathrm{C}$, et al. Advancing research diagnostic criteria for Alzheimer's disease: the IWG-2 criteria. Lancet Neurol. 2014;13(6): 614-29.

49. Beauchet O, Allali G, Annweiler C, et al. Association of Motoric Cognitive Risk Syndrome with Brain Volumes: results from the GAIT study. J Gerontol A Biol Med Sci. 2016;71(8):1081-8.

50. Mergeche $J$, Verghese J, Allali G, et al. White matter Hyperintensities in older adults and motoric cognitive risk syndrome. J Neuroimaging Psychiatry Neurol. 2016;1(2):73-8.

51. Wang N, Allali G, Kesavadas C, et al. Cerebral small vessel disease and motoric cognitive risk syndrome: results from the Kerala-Einstein study. J Alzheimers Dis. 2016:50(3):699-707.

52. Reed BR, Eberling JL, Mungas D, et al. Frontal lobe hypometabolism predicts cognitive decline in patients with lacunar infarcts. Arch Neurol. 2001;58(3): 493-7.

53. Takakusaki K. Neurophysiology of gait: from the spinal cord to the frontal lobe. Mov Disord. 2013;28(11):1483-91.

54. Buchman AS, Yu L, Wilson RS, et al. Association of brain pathology with the progression of frailty in older adults. Neurology. 2013;80(22):2055-61.

55. Wallace $\mathrm{L}$, Theou O, Rockwood K, et al. Relationship between frailty and Alzheimer's disease biomarkers: a scoping review. Alzheimers Dement. 2018; 10:394-401.

56. Nadkarni NK, Perera S, Snitz BE, et al. Association of Brain Amyloid-beta with Slow Gait in elderly individuals without dementia: influence of cognition and Apolipoprotein E epsilon4 genotype. JAMA Neurol. 2017; 74(1):82-90.

57. Buchman AS, Wilson RS, Bienias JL, et al. Change in body mass index and risk of incident Alzheimer disease. Neurology. 2005;65(6):892-7.

58. van Norden AG, Fick WF, de Laat KF, et al. Subjective cognitive failures and hippocampal volume in elderly with white matter lesions. Neurology. 2008; 71(15):1152-9.

59. Striepens N, Scheef L, Wind A, et al. Volume loss of the medial temporal lobe structures in subjective memory impairment. Dement Geriatr Cogn Disord. 2010;29(1):75-81.
60. Mosconi L, De Santi S, Brys M, et al. Hypometabolism and altered cerebrospinal fluid markers in normal apolipoprotein E E4 carriers with subjective memory complaints. Biol Psychiatry. 2008;63(6):609-18.

61. Scheef L, Spottke A, Daerr M, et al. Glucose metabolism, gray matter structure, and memory decline in subjective memory impairment. Neurology. 2012;79(13):1332-9.

62. Chong E, Ho E, Baldevarona-Llego J, et al. Frailty and Risk of Adverse Outcomes in Hospitalized Older Adults: A Comparison of Different Frailty Measures. J Am Med Dir Assoc. 2017;18(7):638 e7-38 e11.

\section{Publisher's Note}

Springer Nature remains neutral with regard to jurisdictional claims in published maps and institutional affiliations.
Ready to submit your research? Choose BMC and benefit from:

- fast, convenient online submission

- thorough peer review by experienced researchers in your field

- rapid publication on acceptance

- support for research data, including large and complex data types

- gold Open Access which fosters wider collaboration and increased citations

- maximum visibility for your research: over $100 \mathrm{M}$ website views per year

At BMC, research is always in progress.

Learn more biomedcentral.com/submissions 